\title{
A NOVEL LINEAR CIRCUIT FOR CURRENT EQUALIZATION IN LED STRINGS
}

\author{
Cláudio R. B. S. Rodrigues ${ }^{1,2}$, Pedro S. Almeida ${ }^{1}$, Guilherme M. Soares ${ }^{1}$, \\ Mateus F. Braga ${ }^{1}$ and Henrique A. C. Braga ${ }^{1}$ \\ ${ }^{1}$ Modern Lighting Research Group (NIMO) - Federal University of Juiz de Fora (UFJF) \\ Campus Universitário, Plataforma 5 - CEP 36036-030 - Juiz de Fora - MG. \\ ${ }^{2}$ IFSEMG - Federal Institute of Education, Science and Technology of the Southeast of Minas Gerais - Campus Juiz de Fora \\ claudio.rodrigues@ifsudestemg.edu.br; henrique.braga@ufjf.edu.br
}

\begin{abstract}
This paper deals with the problem of current sharing in parallel strings of LEDs. As there is no guarantee that the string voltages are the same, some strategy for equalizing their currents must be used. This ensures that the luminous fluxes emitted by the strings are very similar. To address this issue it is proposed a small and simple linear topology that can be used on a number of series-associated LEDs, working as a constant current source for each string. Only four components are used in the arrangement, and a low dependence on transistor parameters is observed, ensuring good current regulation. Mathematical description and an analysis of the stability of the circuit are provided, as well as experimental results.
\end{abstract}

Keywords - LEDs; LED string driving; Current equalization; Solid state lighting.

\section{INTRODUCTION}

During many years LEDs were employed as luminous flags and indicators, but due to the development of the blue LED (which allowed the realization of white LEDs) they have recently found their place in general lighting applications. This was made possible by the recent advent of the so-called high-brightness LEDs (HB-LEDs), which are changing the perspectives of indoor as well as outdoor illumination.

Long term estimations assuming $100 \%$ market penetration and $50 \%$ power conversion efficiency are that a $10 \%$ decrease on worldwide energy consumption could be attained by using LEDs as main light sources. This saving goal could means a 50\% decrease on the electrical energy used for producing artificial lighting [1]. That, together with the white light, good color rendering index (CRI) and long lifespan makes LEDs a very attractive and environmentally friendly alternative as a light source.

But since HB-LEDs are essentially low power devices (usually 1 to $5 \mathrm{~W}$ ), an LED-luminaire (or anything equivalent of a lamp made out of LEDs) could not be constructed out of a single device. Thus, it is necessary to associate a number of LEDs in order to produce the desired light output. There are several ways to associate LEDs to obtain the desired luminous flux. Each form of association has its advantages and disadvantages, as will be discussed.

Artigo submetido em 19/11/2012. Revisado em 16/01/2013. Aceito para publicação em 27/02/2013 na Sessão Especial por recomendação do editor Ricardo Nederson do Prado.
The main objective of this work is to propose a novel circuit to perform current balancing in series-parallel strings of LEDs. Experimental validation of the topology is provided in a two string module.

\section{LEDS ARRANGEMENTS}

The LED-based solutions need to have multiple LEDs associated to emit the luminous flux of typical luminaires. As an example, a $1 \mathrm{~W}$ LED emits around $100 \mathrm{~lm}$, while a $100 \mathrm{~W}$ HPS lamp emits $9,000 \mathrm{~lm}$. So, it would be necessary an association of 90 unities of $1 \mathrm{~W}$ LED in order to have the same luminous flux.

The association of LEDs to make a string module raises concern on the current regulation of the individual devices or strings. Since light output and correlated color temperature are highly dependent on the forward current of an LED [2], there is a great deal of care to drive all the devices in a single string (or string module) under the same forward current. Furthermore, overcurrent can cause the acceleration of the LED luminous flux degradation.

Also, there is the possibility of an LED failure, under which different associations (shown in Figure 1) will respond in different manners. According to [3], LEDs tend to commonly fails as an open circuit under electrostatic discharge (ESD) and thermo-mechanical stress of the bond wires. But they can also fail as a short circuit, prevalently ondie, as a result of threading dislocations (formation of nanopipes on the substrate) or degraded passivation (defects on the insulating $\mathrm{SiO}_{2}$ layer). It is important to say that the most modern LED models do not have a $\mathrm{SiO}_{2}$ layer [4].

A few possibilities for associating LEDs to form a string or luminaire module are shown in Figure 1. A pure series association of LEDs (Figure 1a), called an LED string, has the advantage of forcing all devices to share the same current, thus making any further current equalization unnecessary, so there is no current imbalance. On the other hand, large series strings could result in high string voltage. Moreover, if a single LED turns out to fail as an open circuit, the whole string will be out (if no special protection circuits are employed), compromising the reliability of the module under this faulty condition.

A parallel association of strings forms a series-parallel LED module (Figure 1b). This reduces the impact of an open circuit LED failure, which would make only a string turn out, but creates a current imbalance issue. Since not all LEDs can be ensured to be identical, the voltage at each string will be slightly different, thus their currents at will also differ. Therefore, it might be necessary some sort of equalization 
circuit to balance the current on the individual strings. A matrix module (Figure 1c) is made by connecting LEDs directly in parallel and then connecting these parallel clusters in series with each other.

The result is that every matrix row of the module shares the same voltage. Once more, current imbalance will take place, because LEDs intrinsically differ in forward voltage. But in this case, it would be necessary an equalization device for each LED, which happens to be unviable. One advantage is that an open circuit failure of an LED will result in only one device out, but if the failure turns out to be a short circuit, a whole parallel cluster will turn off due to the voltage drop to zero.

\section{CURRENT EQUALIZATION TECHNIQUES FOR LEDS STRINGS}

The series-parallel association of LEDs is an alternative that may be considered more reliable, in terms of failure (considering the case of open circuit failure) than the pure series strings and at the same time, easier to ensure the current balancing than the matrix modules. Therefore, the only problem to be solved is how to equalize the currents at the parallel-associated strings.

A number of circuits and techniques have been proposed for equalizing the current in LED strings, ranging from fairly simple to more intricate topologies. Most of these circuits assume a constant voltage bus or a current source, from where the LEDs and equalization circuits are fed. An adequate switching regulator, as shown in Figure 2, can provide this bus.

Some of the techniques use monolithic linear regulators, such as LM317, plus a pass transistor to provide the strings with regulated, equalized currents [5]. This provides a fairly simple circuit, but the efficiency can be quite low for the higher currents required by power HB-LEDs, because the regulator IC requires a minimum voltage drop from input to output for the circuit to work (Figure 3).

Another linear alternative are MOSFET-based current mirrors [6]. A reference branch MOSFET, which has its gate connected to other branches of LED strings, forces the mirroring of the reference current on these strings. This circuit only works satisfactorily if the MOSFETs are of highgain and are identical (or very alike), which is an almost impossible condition for discrete power MOSFETs. However, it could be useful in the case MOSFETs inside an integrated circuit were adopted.

Another relative disadvantage concerning the reference [6] alternative is that the reference branch drains current without any useful output, and the circuit uses as many MOSFETs as LED strings (Figure 4).

A more intricate circuit is presented in [7]. It uses a linear regulator along with a feedback loop to control the switching pre-regulator, in order to adapt the output voltage to attain high efficiency (Figure 5).

There are also the switching alternatives for current equalization. For example, one presented in [8] uses an inverter based on the current-fed parallel-resonant push-pull topology. The LEDs are connected in anti-parallel at the output of the inverter, two-by-two, series-connected to a current balancing capacitor. The LEDs are fed by half-wave rectified high-frequency quasi-sinusoidal current and zerovoltage switching can be attained, thus also higher efficiency.

Some other more intricate switching circuits are proposed by [9] and [10], and a hybrid switching-magnetic solution is proposed in [11]. The switching solutions are more varied and complex by definition, and will not be further explored in this work. Table I shows some characteristics for both linear and switching equalization circuits, aiming a brief comparison among them.

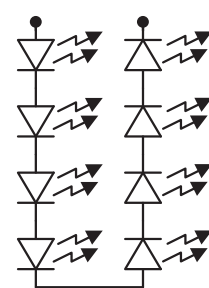

(a)

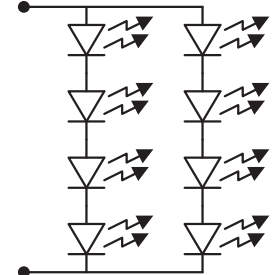

(b)

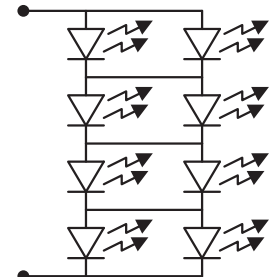

(c)
Fig. 1. Three possibilities of LED string modules: (a) series string, (b) series-parallel string module and (c) matrix module.

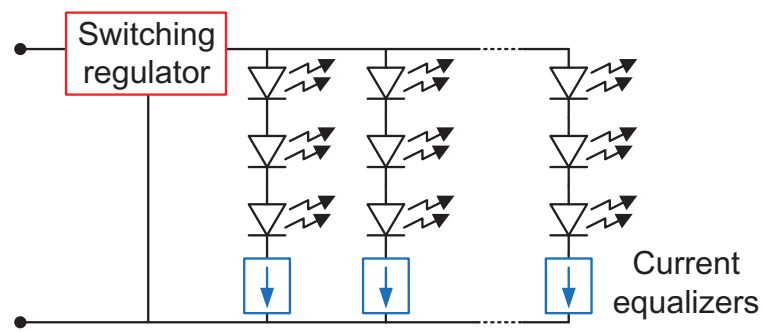

Fig. 2. Basic scheme of a series-parallel modular HB-LED driver.

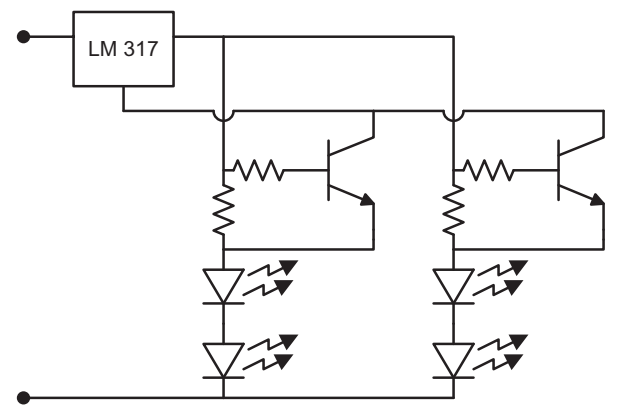

Fig. 3. Linear current equalizer using monolithic regulator IC.

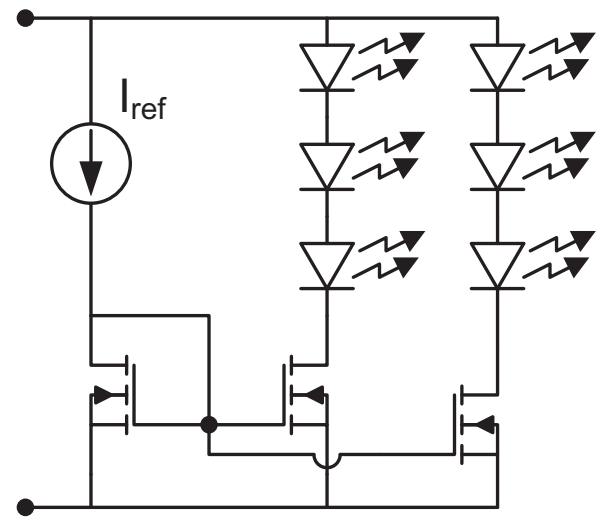

Fig. 4. Linear current equalizer using current mirrors. 


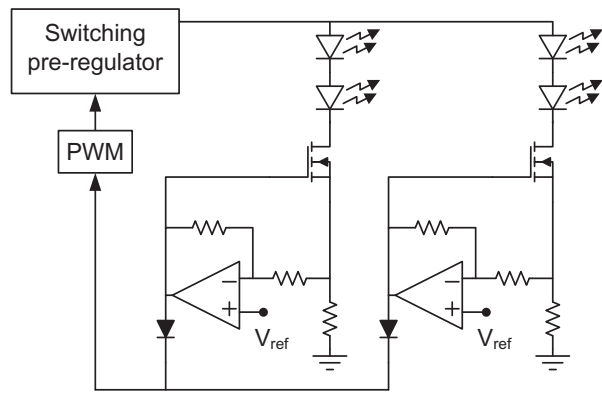

Fig. 5. Linear current equalizer using adaptive voltage drive voltage.

Linear circuits, though commonly more inefficient, are generally easier to implement, can be considered costeffective alternatives and represent reliable enough solutions for mass-manufacturing luminaires. Moreover, they usually require a lower component count.

Recently, many passive equalization circuits have been proposed [12] - [15], which reveal the importance of this subject for this specific field. All of them add characteristics of low cost, high efficiency and good precision in current balancing. In this way, a novel linear alternative is proposed in the next section.

\section{PROPOSED CIRCUIT AND ANALYSIS}

The linear current equalizer for parallel LED strings being evaluated in this paper is depicted in Figure 6. It has been introduced for the very first time by the authors in [16]. This circuit employs only two low power resistors, one signal bipolar transistor and one monolithic Darlington-pair transistor, in order to act as a constant current source for each string of LEDs.

The strings are assumed to be fed by a constant voltage (e.g., from a switching regulator) that is slightly higher than the string voltage itself. One of the main advantages is that this voltage difference can be extremely low, circa 1 volt.

The circuit works by forcing the current that feeds the LEDs on the collector of the transistor $\mathrm{Q}_{1}$ to be almost equal to the constant current at its emitter. $\mathrm{Q}_{2}$ is used to provide a constant voltage reference for the current-defining (shunt) resistor $\mathrm{R}_{\mathrm{S}}$, as low as possible in order to avoid great losses on the circuit of Figure 6. Proposed current equalizer circuit, here shown for two LED strings.

TABLE I

Comparison Between Equalizing Techniques

\begin{tabular}{lcc}
\hline & Switching Solutions & Linear Solutions \\
\hline Operating frequency & High & Low (DC) \\
\hline Current balancing & $\begin{array}{c}\text { Complexity- } \\
\text { dependent }\end{array}$ & Fair to good \\
\hline EMI & Moderate to high & Low to none \\
\hline Cost & Moderate to high & Low \\
\hline Component count & Medium to high & Low \\
\hline Reliability & $\begin{array}{l}\text { Complexity- } \\
\text { dependent }\end{array}$ & High \\
\hline Efficiency & High & $\begin{array}{l}\text { Input voltage- } \\
\text { dependent }\end{array}$ \\
\hline Heating & Moderate to low & Moderate to high \\
\hline
\end{tabular}

It is important to stress that a complementary PNP version of the circuit could also be implemented, using a similar analysis to the described below.

Assuming that both transistors $\mathrm{Q}_{1}$ and $\mathrm{Q}_{2}$ are operated at active-mode and their current gains being given by $\beta_{1}$ and $\beta_{2}$, respectively, (1) follows.

$$
i_{L E D}=i_{E} \frac{\beta_{1}}{\beta_{1}+1}
$$

Since $\beta_{1}$ has a very large value, due to the Darlington-pair configuration, and $\mathrm{Q}_{2}$ is a high-gain signal transistor with low base current, the approximation (2) can be used.

$$
i_{L E D} \approx i_{E}=\frac{V_{B E}}{R_{S}}
$$

Thus, the LED string current is a function solely of two constants: the base-emitter voltage of $\mathrm{Q}_{2}$ and the value of the resistor $\mathrm{R}_{\mathrm{S}} . \mathrm{V}_{\mathrm{BE}}$ is only dependent on the chosen transistor $\mathrm{Q}_{2}$.

The polarizing current $i_{P}$ could be small, enough only to produce the voltage reference for $\mathrm{Q}_{2}$. The voltage across the LED string is given by the estimated voltage of one device times the number of series associated LEDs ( $\left.n . V_{\text {LED }}\right)$. Thus, the theoretical efficiency of the circuit $(\eta)$ can be obtained as the ratio between output and input powers, which is approximated by (3).

$$
\eta=\frac{P_{L E D}}{P_{i n}}=\frac{n \cdot V_{L E D} \cdot i_{L E D}}{\left(i_{P}+i_{L E D}\right) V_{D C}} \approx \frac{n \cdot V_{L E D}}{V_{D C}}
$$

Figure 7 shows the theoretical bus voltage as a function of the number of LEDs of a given string, taking the equalizer efficiency as a parameter, according to equation (3). Dashed line represents the minimum practical bus voltage required for the equalizer circuit to work properly, assuming maximum efficiency and taking into account the typical collector-to-emitter saturation voltage $(0.7 \mathrm{~V})$ as well as the base-to-emitter $\mathrm{Q}_{2}$ voltage $(0.6 \mathrm{~V})$. So, by using this chart one can determine the bus voltage needed in order to attain a desired equalizer efficiency, for a determined number of LEDs on the strings.

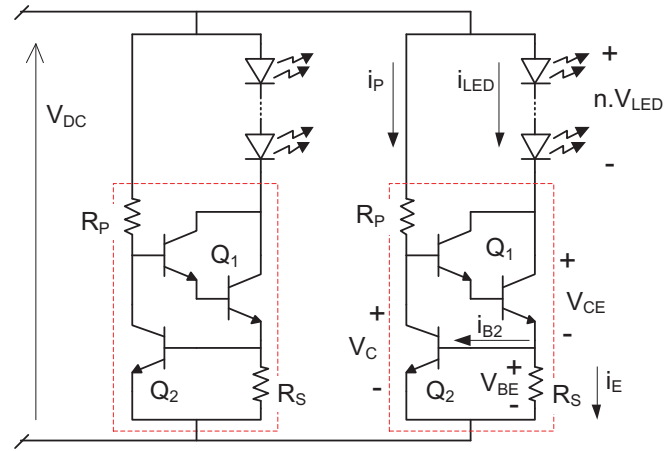

Fig. 6. Proposed current equalizer circuit, here shown for two LED strings. 


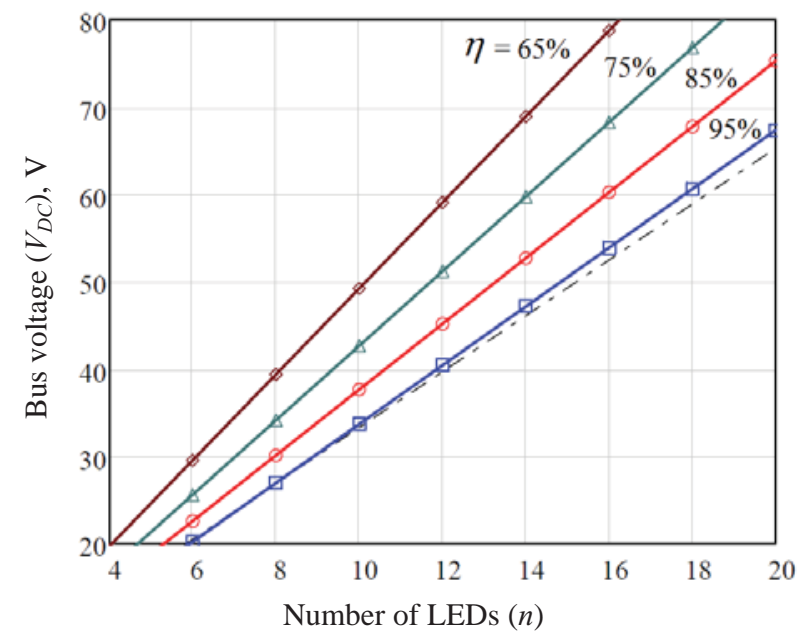

Fig. 7. Bus voltage as function of the number of LEDs for various theoretical efficiency values (parameterized).

\section{DESIGN GUIDELINE AND CONSIDERATIONS}

Equation (3) shows that the efficiency of the circuit is directly proportional to the number of series associated LEDs in a single string. Therefore, this could be used as a design guideline: using as long as possible strings and as low as possible input voltage for attaining high efficiencies. This idea could be also implemented at the control loop of the switching pre-regulator assumed to be present before the equalizers, playing the role of a maximum efficiency point tracker.

For a practical design to work, the transistor $\mathrm{Q}_{1}$ must be working at active-mode. In order to ensure this operating condition, its collector-emitter voltage $\mathrm{V}_{\mathrm{CE}}$ should be kept at a higher value than the saturation voltage of this device, $\mathrm{V}_{\mathrm{CE} \text {,sat }}$. These considerations impose a bottom limit for the input voltage, given by (4).

$$
V_{D C} \geq n \cdot V_{L E D}+V_{C E, s a t}+V_{B E}
$$

The maximum efficiency of the design will be attained at the lower limit imposed by (5), thus defining $\mathrm{V}_{\mathrm{DC}}$.

The voltage at the collector of transistor $\mathrm{Q}_{2}\left(\mathrm{~V}_{\mathrm{C}}\right)$ can be used to define the polarizing resistor $R_{p}$, leading to (6).

$$
R_{P}=\frac{V_{D C}-V_{C}}{i_{P}} \cong \frac{V_{D C}-3 . V_{B E}}{i_{P}}
$$

The polarizing current $i_{P}$ could be chosen to assume a value between $100 \mu \mathrm{A}$ and $1 \mathrm{~mA}$ for a small-signal transistor

Finally, the current defining resistor $\mathrm{R}_{\mathrm{S}}$ could be chosen by modifying (2) to (6).

$$
R_{S}=\frac{V_{B E}}{i_{L E D}}
$$

The power rating of this device $\left(\mathrm{P}_{\mathrm{RS}}\right)$ is always a constant value, dependent on LED and transistor parameters together, and given by (7) .

$$
P_{R S}=R_{S} \cdot i_{L E D}^{2}=V_{B E} \cdot i_{L E D}
$$

The power rating of the RS resistor is less than half a watt for the common power LEDs that operate on currents below $700 \mathrm{~mA}$. This means that a small signal resistor can be used.

These design guidelines can be easily applied to obtain a working prototype in order to test the circuit's performance.

\section{PROTOTYPE DESIGN AND EXPERIMENTAL RESULTS}

A prototype for a two-string LED module is proposed for design validation. A photograph of the LED module plus the built-in prototype is shown in Figure 8. The strings are composed of 16 series-connected OSRAM LUW W5PM Golden DRAGON Oval Plus LEDs. These LEDs have a typical light output of 106 lumens each at a drive current of $350 \mathrm{~mA}$, while having a typical forward voltage of $3.2 \mathrm{~V}$ at the same current [17].

This gives a two-string module of 32 LEDs, with a nominal light output of almost 3400 lumens, which is closely equivalent to a $35 \mathrm{~W}$ metal-halide lamp. Each string will have an approximate voltage of $51.2 \mathrm{~V}$ and the whole module is expected to demand something close to $36 \mathrm{~W}$.

For the current equalizer, the transistors chosen were a small-signal BC547A NPN for the polarizing branch and a TIP110 NPN Darlington for the LED string branch. These devices are high-gain transistors, suitable for this design.

The transistors' electrical parameters of interest were experimentally evaluated. The $\mathrm{V}_{\mathrm{BE}}$ voltage of $\mathrm{Q}_{2}$ transistor was found to be $0.6 \mathrm{~V}$ when forward-biased at $\mathrm{i}_{\mathrm{P}}=500 \mu \mathrm{A}$. As for the saturation voltage of $\mathrm{Q}_{1}, \mathrm{~V}_{\mathrm{CE} \text {,sat }}$, it was measured $0.7 \mathrm{~V}$ at $350 \mathrm{~mA}$. The parameters of the design are shown in Table II.

From (4), it is possible to derive the minimum bus voltage for feeding the LED module: $\mathrm{V}_{\mathrm{DC}} \geq 52.5 \mathrm{~V}$. Using this value, the resistance of $R_{P}$ is calculated from (5), being $R_{P} \cong$ $100 \mathrm{k} \Omega$.

The current defining resistor is calculated from (6) as being $\mathrm{R}_{\mathrm{S}}=1.7 \Omega$. These prototype components are summarized in Table III.

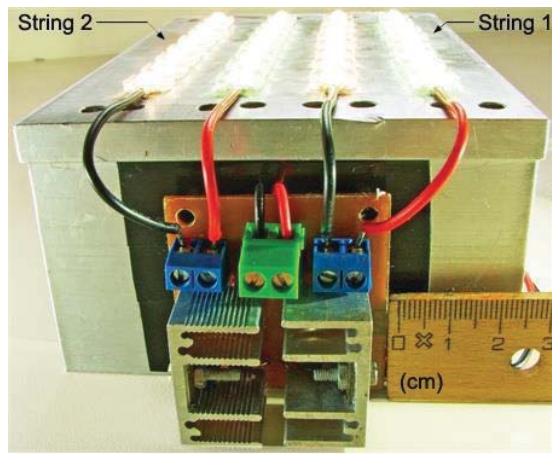

Fig. 8. Current equalizer circuit on two-string $36 \mathrm{~W}$ LED module. 
TABLE II

Design Parameters

\begin{tabular}{ccc}
\hline Symbol & Value & Parameter \\
\hline $\mathrm{i}_{\mathrm{LED}}$ & $350 \mathrm{~mA}$ & LED string current \\
\hline $\mathrm{V}_{\mathrm{LED}}$ & $3.2 \mathrm{~V}$ & LED forward voltage drop \\
\hline $\mathrm{N}$ & 16 & number of LEDs in a string \\
\hline $\mathrm{i}_{\mathrm{P}}$ & $500 \mu \mathrm{A}$ & polarizing current \\
\hline $\mathrm{V}_{\mathrm{BE}}$ & $0.6 \mathrm{~V}$ & base-emitter voltage of Q2 \\
\hline $\mathrm{V}_{\mathrm{CE}, \text { Sat }}$ & $0.7 \mathrm{~V}$ & saturation voltage of Q1
\end{tabular}

The experimental results of each string are presented together in Figure 9. The input measured input voltage and current was, respectively $52.4 \mathrm{~V}$ and $705.3 \mathrm{~mA}$, as shown in Table IV together with the most relevant experimental data. Module efficiency (strings plus equalizer) was measured $93.6 \%$, at full power.

\section{TEST UNDER FAULTY CONDITIONS}

For testing the behavior of the circuit under LED failure, were considered both scenarios - open circuit and short circuit failures.

If one LED fails open, his whole string will turn off, but the other strings will remain current-regulated by the other independent equalizing circuits, and no damage will be caused to them or the LEDs. The module would remain working, although the light output would decrease by a factor of $1 / \mathrm{k}$, where $\mathrm{k}$ is the number of strings being fed, for each string that is put out (e.g., one string out of two means a $50 \%$ reduction; two strings out of three means a $66 \%$ luminosity reduction).

On the other hand, a short circuit failure would apply an overvoltage on the devices, in case there was no current equalizing circuit. But the proposed scheme is intended to compensate this kind of failure, by maintaining the current regulated and equalized throughout the strings.

Since shorts are the most common failure mode of LEDs [18] and also have a more significant impact for the equalizing circuit proposed, a failure test was conducted, with different numbers of LEDs in different strings failing short. The current at each string was measured in all cases, to ensure that equalization would still take place even under abnormal conditions. The results of these tests are presented at Table V.

TABLE III

Prototype Components

\begin{tabular}{ccc}
\hline Symbol & Value & Parameter \\
\hline $\mathrm{R}_{\mathrm{S}}$ & $1.7 \Omega$ & current defining resistor \\
\hline $\mathrm{R}_{\mathrm{P}}$ & $100 \mathrm{k} \Omega$ & polarizing branch resistor \\
\hline $\mathrm{V}_{\mathrm{DC}}$ & $52.5 \mathrm{~V}$ & bus input voltage \\
\hline
\end{tabular}

TABLE IV

Experimental Results

\begin{tabular}{cccc}
\hline Measurement point & Current & Voltage & Power \\
\hline String 1 & $350.1 \mathrm{~mA}$ & $49.72 \mathrm{~V}$ & $17.4 \mathrm{~W}$ \\
\hline String 2 & $344.7 \mathrm{~mA}$ & $49.84 \mathrm{~V}$ & $17.2 \mathrm{~W}$ \\
\hline Input & $705.3 \mathrm{~mA}$ & $52.4 \mathrm{~V}$ & $36.96 \mathrm{~W}$ \\
\hline
\end{tabular}

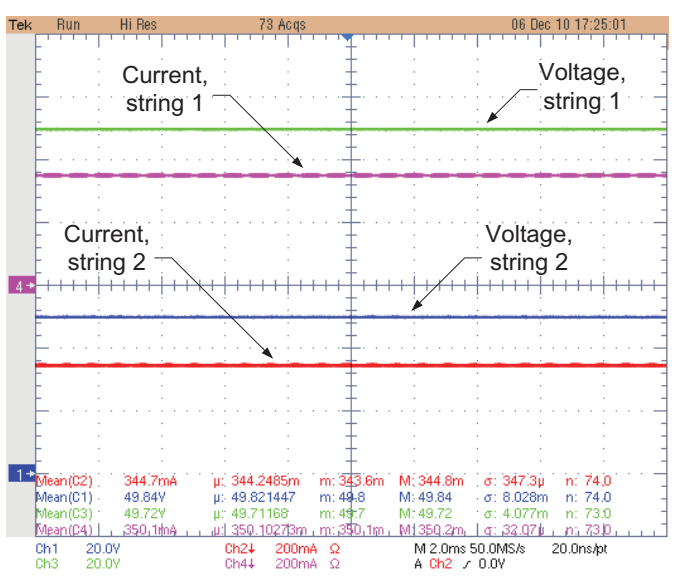

Fig. 9. Current and voltage of both LED strings (200 mA/div; $20 \mathrm{~V} /$ div).

The small difference between values in a same string suggests that the measured discrepancies are only ordinary fluctuations on current. In this case, the circuit is able to sustain equalization under LED short circuit failures satisfactorily.

\section{EQUALIZING STABILITY EVALUATION}

In the design of a transistor circuit, the bias point (Q) is carefully established so that the transistor operates in a specified range ensuring linear operation. Once the design is finished, it is necessary to check the operation point variations due to temperature changes and possible amplifier parameters variations.

The relationship between a given change in collector current against a change in the parameter that caused current deviation is called stability factor. The stability factor is therefore a measure of how sensitive is the bias collector current when submitted to fluctuations in some influence parameter [19] e [20].

In the section of equalization circuit design it was considered that the base current of transistor $\mathrm{Q}_{2}$ was very small in comparison with the current flowing through the resistor $\mathrm{R}_{\mathrm{s}}$. For the analysis in this section, however, it will be assumed that this current is not null (i.e. the current through the Darlington emitter equals the sum of the shunt resistor current and $\mathrm{Q}_{2}$ base current, according to Figure 6). This consideration allows observing the dependence of the LEDs current with the main influence parameters of transistor $\mathrm{Q}_{2}$. Thus, the current $\mathrm{I}_{\mathrm{LED}}$ can be written as in (8).

Regarding the uncertainties on the shunt resistor value and temperature, the stability factors are given by the partial derivative of these equations (i.e., $S_{x}=\partial I_{L E D} / \partial x$ ), being $x$ the interest parameter.

TABLE V

LED Failure Test - Short Circuit Failure

\begin{tabular}{ccccc}
\hline $\begin{array}{c}\text { Number of } \\
\text { failed devices }\end{array}$ & $\begin{array}{c}\text { String of } \\
\text { Failure }\end{array}$ & $\begin{array}{c}\text { Current } \\
\text { through str. 1 }\end{array}$ & $\begin{array}{c}\text { Current } \\
\text { through str. 2 }\end{array}$ & $\begin{array}{c}\text { Theoretical } \\
\text { Efficiency }\end{array}$ \\
\hline 1 LED & String 1 & $349.1 \mathrm{~mA}$ & $343.9 \mathrm{~mA}$ & $91.4 \%$ \\
\hline 3 LEDs & String 1 & $348.1 \mathrm{~mA}$ & $344.3 \mathrm{~mA}$ & $79.2 \%$ \\
\hline 1 LED & String 2 & $349.5 \mathrm{~mA}$ & $345.5 \mathrm{~mA}$ & $91.4 \%$ \\
\hline 3 LEDs & String 2 & $348.7 \mathrm{~mA}$ & $344.4 \mathrm{~mA}$ & $79.2 \%$ \\
\hline
\end{tabular}




$$
\begin{aligned}
& I_{L E D}=\left(I_{B 2}+I_{E}\right)\left(\frac{\beta_{1}}{\beta_{1}+1}\right)+I_{C B O 1}= \\
& \left(\frac{I_{S 2} e^{\frac{V_{B E 2}}{V_{T}}}}{\beta_{2}}+\frac{V_{B E 2}}{R_{S}}\right)\left(\frac{\beta_{1}}{\beta_{1}+1}\right)+I_{C B O 1}
\end{aligned}
$$

where:

$\mathrm{I}_{\mathrm{B} 2}$ is the BC547A base current

$\mathrm{I}_{\mathrm{E}}$ is the Darlington emitter current

$\mathrm{I}_{\mathrm{S} 2}$ is the saturation current of BC547A transistor;

$\mathrm{V}_{\mathrm{BE} 2}$ is the emitter-base voltage of BC547A transistor;

$\mathrm{V}_{\mathrm{T}}$ is the thermal voltage;

$\mathrm{I}_{\mathrm{CBO} 1}$ is the Darlington collector cutoff current;

$\beta_{1}$ and $\beta_{2}$ are the Darlington and BC547A gains, respectively.

To take into account the uncertainty of the transistors gains, it is necessary to analyze the real increment, since this variation can be very large. The stability factors of interest to this study are shown in (9) to (16).
Considering all the interest parameter variations, a general equation for the variation on $\mathrm{I}_{\mathrm{LED}}$ can be written in its generic form, as given by (17).

In equations (15) and (16), the LEDs current over which the stability factor is calculated has been named ILEDref.

Table VI shows the parameters variations considered in this analysis.

According to the type of evaluation to be performed, some parameters variations should be neglected. For example, in the analysis of the effect of temperature variation, the variation in the $I_{L E D}$ equation is not dependent on the uncertainty of the components. Similarly, concerning the uncertainty on components values, the influence of the temperature on $\mathrm{I}_{\text {LED }}$ should be disregarded.

From (17) it can be seen that a small stability factor leads to small variations in $\mathrm{I}_{\mathrm{LED}}$ due to the oscillations of the related parameter.

Using the equations given before it was firstly carried out some calculations for a variation of $75^{\circ} \mathrm{C}$ in temperature $\left(25^{\circ} \mathrm{C}\right.$ to $\left.100^{\circ} \mathrm{C}\right)$. By analyzing the variation in $\mathrm{I}_{\mathrm{LED}}$ due to variations in temperature, it will be considered that $\Delta_{\mathrm{Rs}}, \Delta_{\beta 1}$ and $\Delta_{\beta 2}$ are null in equation (17).

$$
\begin{aligned}
& S_{I_{C B O 1}}=1 \\
& S_{R_{S}}=-\left(\frac{V_{B E 2}}{R_{S}^{2}}\right)\left(\frac{\beta_{1}}{\beta_{1}+1}\right) \\
& S_{V_{B E 2}}=\left(\frac{I_{s 2}}{\beta_{2}} \frac{1}{V_{T}} e^{\frac{V_{B E 2}}{V_{T}}}+\frac{1}{R_{S}}\right)\left(\frac{\beta_{1}}{\beta_{1}+1}\right) \\
& S_{V_{T}}=-\left(\frac{I_{s 2}}{\beta_{2}} \frac{V_{B E 2}}{\mathrm{~V}^{2}{ }_{\mathrm{t}}} e^{\frac{V_{B E 2}}{V_{T}}}\right)\left(\frac{\beta_{1}}{\beta_{1}+1}\right) \\
& S_{\beta_{1} T}=\left(\frac{\beta_{2} V_{B E 2}+I_{S 2} R_{s} e^{\frac{V_{B E 2}}{V_{T}}}}{\beta_{2} R_{s}\left(\beta_{1}+1\right)}\right)-\frac{\beta_{1}\left(\beta_{2} V_{B E 2}+I_{s 2} R_{S} e^{\frac{V_{B E 2}}{V_{T}}}\right)}{\beta_{2} R_{S}\left(\beta_{1}+1\right)^{2}} \\
& S_{\beta_{2} T}=-\frac{I_{s 2} \cdot e^{\frac{V_{B E 2}}{V_{T}}}}{\beta_{2}}\left(\frac{\beta_{1}}{\beta_{1}+1}\right) \\
& S_{\beta_{1}}=\frac{I_{\text {LEDref }} \cdot\left(\frac{I_{S 2} e^{\frac{V_{B E 2}}{V_{T}}}}{\beta_{2}}+\frac{V_{B E 2}}{R_{S}}\right)}{\left(\left(\frac{I_{S 2} \cdot e^{\frac{V_{B E 2}}{\beta_{T}}}}{\beta_{2}}+\frac{V_{B E 2}}{R_{S}}\right) \beta_{1 \text { min }}+\left(\beta_{1 \text { min }}+1\right)\right)\left(\beta_{1 \max }+1\right)} \\
& S_{\beta_{2}}=-\frac{I_{\text {LEDref }} I_{S 2} e^{\frac{V_{B E 2}}{V_{T}}}\left(\frac{\beta_{1}}{\beta_{1}+1}\right)}{\beta_{2 \max }\left[\left(I_{S 2} e^{\frac{V_{B E 2}}{V_{T}}}+\beta_{2 \min } \frac{V_{B E 2}}{R_{S}}\right)\left(\frac{\beta_{1}}{\beta_{1}+1}\right)+\beta_{2 \min } I_{C B O 1}\right]} \\
& \Delta \mathrm{I}_{\mathrm{LED}}=S_{I_{C B O 1}} \Delta \mathrm{I}_{\mathrm{CBO} 1}+S_{V_{B E 2}} \Delta V_{B E 2}+S_{R_{S}} \Delta R_{S}+S_{V_{T}} \Delta V_{T}+S_{I_{S 2}} \Delta I_{s 2}+S_{\beta_{1 T}} \Delta \beta_{1 T}+S_{\beta_{2 T}} \Delta \beta_{2 T}+S_{\beta_{1}} \Delta \beta_{1}+S_{\beta_{2}} \Delta \beta_{2}
\end{aligned}
$$


TABLE VI

Parameters variation

\begin{tabular}{cc}
\hline Fluctuation & Equation/Value \\
\hline$\Delta \mathrm{I}_{\mathrm{CBO1}}$ & $I_{\text {CBO1initial }}\left(e^{K_{1} \cdot \Delta T}-1\right), K_{1}=0.07 /{ }^{\circ} \mathrm{C}$ \\
\hline$\Delta V_{B E 2}$ & $-K_{2} \Delta T, K_{2}=2.5 \mathrm{mV} /{ }^{\circ} \mathrm{C}$ \\
\hline$\Delta R_{S}$ & $\left(R_{S}+R_{S}\right.$ doubt $)-\left(R_{s}-R_{S}\right.$ doubt $)$ \\
\hline$\Delta V_{T}$ & $\frac{V_{\text {Tinitial }} \Delta T}{T_{\text {initial }}}, T_{\text {initial }}=$ Initial temperature \\
\hline$\Delta I_{S 2}$ & $\frac{I_{\text {s2initial }} \Delta T}{5}$ \\
\hline$\Delta \beta_{1 T}$ & $3875^{*}$ \\
\hline$\Delta \beta_{2 T}$ & $100^{*}$ \\
\hline$\Delta \beta_{1}$ & $3000^{*}$ \\
\hline$\Delta \beta_{2}$ & $200^{*}$ \\
\hline \multicolumn{2}{c}{$*$ Deviation values were taken from the } \\
& component datasheet [21].
\end{tabular}

Table VII shows the information about the typical BC547A transistor $\left(\mathrm{Q}_{2}\right)$ parameter values at a temperature of $25{ }^{\circ} \mathrm{C}$. It was observed an increase of $22 \%$ in the LEDs current for a variation of $75^{\circ} \mathrm{C}$ in the circuit temperature.

It is important to stress that the variation of $75^{\circ} \mathrm{C}$ is quite high. So, for practical purposes, it would be expected a much lower deviation on LEDs current.

To identify the main causes of the calculated current deviation, it was computed the changes in $\mathrm{I}_{\mathrm{LED}}$ for each parameter that depends on temperature. Thus, it was observed that the variable $\mathrm{I}_{\mathrm{CBO} 1}$ has the greater interference in the bias point and may result in an increase of up to $54 \%$ on the initial current $\mathrm{I}_{\text {LEDref }}$ ). This is because the employed transistor (Darlington TIP110) has a high collector cutoff current (about $1 \mathrm{~mA}$ ). Another variable that interferes greatly in $\mathrm{I}_{\mathrm{LED}}$ is $\mathrm{V}_{\mathrm{BE} 2}$. This one, when analyzed alone, implied in a decrease of $31 \%$ on the initial current. The uncertainties on the other variables considered here resulted in little influence on LEDs current, not exceeding $1 \%$ of the initial value.

One way to reduce the overall change of $\mathrm{I}_{\mathrm{LED}}$ when subjected to temperature variations would be to replace the Darlington transistor for a different model with similar characteristics but featuring an $\mathrm{I}_{\mathrm{CBO}}$ of $0.5 \mathrm{~mA}$ or lower.

With this change, the variation on $\mathrm{I}_{\mathrm{LED}}$ due to $\mathrm{V}_{\mathrm{BE} 2}$ and $\mathrm{I}_{\mathrm{CBO} 1}$ practically cancel each other, reducing the overall variation to less than $1 \%$.

Table VII

Typical values of $\mathrm{BC} 547 \mathrm{~A}$ parameters at $25^{\circ} \mathrm{C}$

\begin{tabular}{cc}
\hline Variable & Typical value at $\mathbf{2 5}^{\circ} \mathbf{C}$ \\
\hline $\mathrm{I}_{\mathrm{CBO} 1}$ & $1 \mathrm{~mA}$ \\
\hline $\mathrm{V}_{\mathrm{BE} 2}$ & $0.6 \mathrm{~V}$ \\
\hline $\mathrm{R}_{\mathrm{s}}$ & $1.7 \Omega$ \\
\hline $\mathrm{V}_{\mathrm{t}}$ & $25.7025 \mathrm{mV}$ \\
\hline $\mathrm{I}_{\mathrm{s} 2}$ & $7.2747 \times 10^{-14} \mathrm{~A}$ \\
\hline$\beta_{1}$ & 2000 \\
\hline$\beta_{2}$ & 220 \\
\hline
\end{tabular}

Values taken from the component datasheet [21].
It is important to observe that the temperature variation occurs in the circuit as a whole, so all LED strings suffer from the same sort of variation in their currents.

Thus, upon temperature variations, it would not be noticed differences in brightness of the LEDs of different strings.

Considering the variation in $\mathrm{I}_{\mathrm{LED}}$ regarding only the uncertainty in $\mathrm{R}_{\mathrm{S}}$, it was concluded that the resistance used must have a class error less than or equal to $1 \%$ since the analysis concerning resistances with $5 \%$ of uncertainties points to an imbalance of up to $10 \%$ on LEDs current from one string to another. This imbalance may generate a difference in the luminous flux emitted by each string, although it may not be perceived by the human eye.

Variations in $I_{L E D}$ due to uncertainties in the values of $\beta_{1}$ and $\beta_{2}$ gains, can be neglected. Typical calculations show that those $\mathrm{I}_{\mathrm{LED}}$ variations should not exceed $1 \%$, even for the worst case deviations in transistor current gains.

As a remark for this topic, it can be said that the sensitivity analysis developed here can be considered reliable enough since its main conclusions are in accordance with the experimental studies of Section VI (measured LED currents present small deviations around theoretical values).

\section{DISCUSSION}

As remarked in this paper, current equalization can have a great impact on the light output of LED modules or luminaires, since small changes in device voltage can yield large changes in current, implying in color and luminous flux deviation, or yet uneven aging of the devices.

Thus, having an equalizing technique or circuit may be mandatory on high power LED drivers, in order to keep reliability and the light quality of these devices.

Low cost solutions, such as simple linear equalizers, may turn out to be a viable way out and can be used in practical or commercial lighting luminaires. Concerning the linear approach proposed here, the low parts count yield reliability and cost-effectiveness, while efficiency-related problems could be countered with proper regulation of input voltage. The evidence for good current balancing is compelling enough to justify the use of such simple circuit.

A possible proposal for a complete LED lighting system employing the linear equalizer addressed in this paper is to employ a switching pre-regulator as the front end of the current balanced strings. As well-known, high power factor switching pre-regulators can feature a high efficiency behavior, which could contribute for a high global efficiency of such an LED lighting arrangement. However, it is also important to implement a feedback control loop that should be able to guarantee the minimum required voltage for the equalization to take place, as depicted in Figure 10 [22].

In this case, it is necessary to measure the string voltage while keeping the bus voltage only higher enough than the string terminal voltage itself. Thus, the highest efficiency possible could be attained for the whole set, as if in a maximum efficiency point tracking control scheme. Such a complete scheme will be discussed in authors' future publications. 


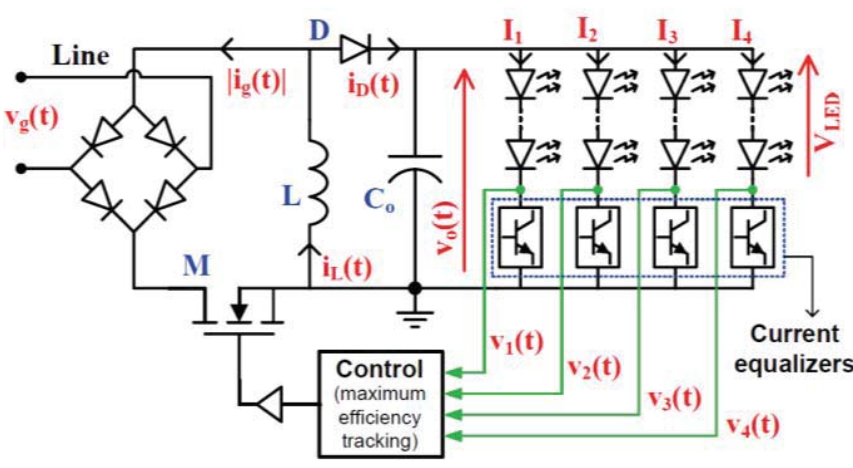

Fig. 10. Possible complete driver topology.

\section{CONCLUSIONS}

This paper introduced a simple technique applied to current equalization of parallel strings of series-associated LEDs.

A brief analysis of circuit operation was carried out and a design guideline has been developed.

The circuit here presented featured a good experimental validation, while relying on only 4 ordinary electronic components.

Furthermore, it achieved an efficiency of almost $94 \%$, while the current deviation between the two LED strings fed through the equalization circuit was only $1.5 \%$. These experimental results should validate both the circuit and the analysis performed, but a brief qualitative comparison between the two mainstream equalizing philosophies was drawn in Table $\mathrm{V}$ in order to point out the limitations of each one, as well as their generalized characteristics.

Also, the behavior of the circuit under LED short circuit failure was investigated. Current equalization was maintained under all tested failures, with the maximum current deviation between the two strings being $1.6 \%$, under abnormal conditions.

It is clear, however, that efficiency will drop when one or more LEDs fail short, due to the intrinsic linear nature of the circuit. Nevertheless, the current on a string containing a short-failed LED will maintain its nominal value, in order not to damage any more devices. Thus, the current equalizer plays its roll on maintaining the reliability of the whole module.

With respect to the stability analysis of the circuit operating point under temperature variations and uncertainties in the values of the components, it can be stated that the structure can feature good stability provided resistors with low tolerance values (less than $1 \%$ ) and Darlington with $\mathrm{I}_{\text {Св } 0}$ close to $0.5 \mathrm{~mA}$ are employed.

Future studies may be proposed to investigate the global electrical and photometrical impact of such an equalization circuit on large LED modules, as in public lighting luminaires and other outdoor and indoor solid-state lighting applications. Furthermore, electrical transients, temperature drift and LED aging effects on the equalizer could be assessed in future work, as well as using more paralleled strings to test the circuit's response when adopted in larger modules.

\section{ACKNOWLEDGEMENT}

Authors would like to thank the financial and technical support from Eletrobras, partial support from $\mathrm{CNPq}$ as well as OSRAM Opto Semiconductors for ceding the LEDs used on the prototype of the luminaire module under which the equalizing circuit was tested.

\section{REFERENCES}

[1] J. Y. Tsao, "Solid state lighting: lamps, chips and materials for tomorrow," IEEE Circuits \& Devices Magazine, vol. 20, no.3, pp. 28-37, 2004.

[2] G. Carraro, "Solving high-voltage off-line HB-LED constant current control-circuit issues," IEEE Applied Power Electronics Conference and Exposition (APEC), pp. 1316-1318, 2007.

[3] J. Arnold, "When the lights go out: LED failure modes and mechanisms," White Paper, Dfr Solutions, College Park, Margland, 2004.

[4] E. F. Schubert, Light Emitting Diodes, Cambridge University Press, 2003.

[5] On Semiconductor, AND8109-D - LED constant current source scheme: theory of operation, Application Note, 2003.

[6] C. Correa, J. Garcia, C. Barriquello, A. Schittler, D. Camponogara and R. N. Prado, "Aplicação de espelhos de corrente no acionamento de LEDs de potência," Congresso Brasileiro de Automática (CBA), 2008. (In Portuguese)

[7] Y. Hu and M. M. Jovanovic, "A novel LED driver with adaptive drive voltage," IEEE Applied Power Electronics Conference and Exposition (APEC), pp. 565-571, 2008.

[8] S. M. Baddela and D. S. Zinger, "Parallel connected LEDs operated at high frequency to improve current sharing," IEEE Industry Applications Conference/39th IAS Annual Meeting, vol. 3, pp. 1677-1681, 2004.

[9] C. Chiu and K. Chen, "A High Accuracy CurrentBalanced Control Technique for LED Backlight," IEEE Power Electronics Specialists Conference (PESC), pp. 4202-4206, 2008.

[10] Texas Instruments, UCC28810EVM-003 - 110-W Multiple String LED Driver with Universal Line Input and PFC, User's Guide, 2009.

[11] K. I. Hwu and S. Chou, "A simple current-balancing converter for LED lighting," IEEE Applied Power Electronics Conference and Exposition (APEC), pp. 587-590, 2009.

[12] J. Zhang, L. Xu, X. Wu, Z. Qian. “A Precise Passive Current Balancing Method for Multioutput LED Drivers," IEEE Transactions on Power Electronics, vol. 26, no. 8, pp, 2149 - 2159, 2011.

[13] K. H. Loo, Y. M. Lai, C. K. Tse. "Design and Analysis of LCC Resonant Network for Quasi-Lossless Current Balancing in Multistring AC-LED Arrays," IEEE Transactions on Power Electronics, vol. 28, no. 2, pp 1047 - 1059, 2013.

[14] C. Zhao, X. Xie, S. Liu. "Multioutput LED Driver With Precise Passive Current Balancing," IEEE Transactions 
on Power Electronics, vol. 28, no. 3, pp 1438 - 1448, 2013.

[15] S. Choi, T. Kim. "Symmetric Current-Balancing Circuit for LED Backlight with Dimming," IEEE Transactions on Industrial Electronics, vol. 59, no. 4, pp $1698-1707,2012$.

[16] P. S. Almeida, J. M. Jorge, C. R. B. S. Rodrigues, G. M. Soares, D. P. Pinto, H. A. C. Braga, "A novel Method of Current Equalization in LED Strings Based on Simple Linear Cicuit," Proc. of IEEE International Symposium on Industrial Electronics (20TH IEEE ISIE). Gdańsk, Poland. June, 2011.

[17] Osram Opto Semiconductors, LUW W5PM Golden Dragon Oval Plus, Datasheet, 2010.

[18] Amtex Electronics, Application Note: 1 - LED Power Supplies, Common LED Configurations, Application Note, 2009.

[19] D. L. Schilling and C. Belove, Electronic Circuits: Discrete and Integrated, McGraw Hill International Edition, 1980.

[20] T. F. Bogart Jr., Electronics devices and circuits, Vol. 1, 3rd edition. Makron Books Ltd, 2001.

[21] General Semiconductors, BC546 thru BC549 - Small Signal Transistors (NPN)," Datasheet, 2009.

[22] P. S. Almeida, J. M. Jorge, D. Botelho, D. Pinto and H. Braga, "Proposal of a Low-Cost LED Driver for a Multistring Street Lighting Luminaire", IEEE Industrial Electronics Conference (IECON 2012), Montreal, October, 2012.

\section{BIOGRAPHIES}

Cláudio Roberto Barbosa Simões Rodrigues was born in Cataguases - MG in 1980. He received the B. S. and M. S. degrees from Federal University of Juiz de Fora, in 2006 and 2009 respectively. In 2012 he fulfilled the studies towards the obtaining of his Ph.D. degree.

Since 2010 he is professor of the Federal Institute of Education, Science and Technology - Campus Juiz de Fora.

His research interests are power electronics applied to lighting systems, public lighting, LEDs characteristics and HID lamps.
Pedro Santos Almeida received the B.S. degree in electrical engineering from the Federal University of Juiz de Fora (UFJF) in 2010, the master degree in 2012 at the same university and is currently pursuing the Ph.D. degree. Since 2008, he has been a researcher at the Modern Lighting Research Group (NIMO) of the School of Engineering. His main research interests are electronic converters for power factor correction, solid-state lighting, discharge lamps, electronic ballasts, modeling and control of converters.

Guilherme Márcio Soares was born in Mercês, Brazil, in 1989. He received the B. S. degree in electrical engineering from the Federal University of Juiz de Fora (UFJF) in 2012 and is currently pursuing the M. S degree.

Since 2010, he has been with in Modern Lighting Research Group (NIMO) at the same university, where he is currently a researcher. His main interests include electronic drivers for LED lighting, spectrophotometry, power factor correction and microprocessors applied to power electronic.

Mateus Freitas Braga was born in Juiz de Fora, Brazil, in 1990. He is currently an undergraduate student in electrical engineering at the Federal University of Juiz de Fora (UFJF), Juiz de Fora, Brazil. Since 2012, he has been with the Modern Lighting Research Group (NIMO) at the same university, where he is currently a researcher.

Henrique Antônio Carvalho Braga obtained the B.Sc. degree in Electrical Engineering from the Federal University of Juiz de Fora (UFJF) in 1982, and teaches in this institution since 1985. He earned the Master degree in Electrical Engineering from COPPE/UFRJ in 1988. In 1996 he attained the doctor degree (Dr. Eng.) in the same field at the Federal University of Santa Catarina, INEP/UFSC. He is currently an Associate Professor at UFJF, teaching in the undergraduate and postgraduate programs in Electrical Engineering, where he is mainly concerned with the subjects of Basic Electronics and Power Electronics. From 2005 to 2006, Prof. Braga has attended a postdoctoral stage at the University of Oviedo in the Spanish city of Gijon, Asturias. He is involved in activities related to Power Electronics, Efficient Lighting and Converters Applied to Renewable Energy. He is a member of SBA, IEEE and SOBRAEP. 